\title{
Polarity in cuticular ridge development and insect attachment on leaf surfaces of Schismatoglottis calyptrata (Araceae)
}

\author{
Venkata A. Surapaneni ${ }^{*} 1,2,3$, Tobias Aust ${ }^{1}$, Thomas Speck ${ }^{1,2,3,4}$ and Marc Thielen ${ }^{1,2,3}$
}

\author{
Full Research Paper \\ Address: \\ ${ }^{1}$ Plant Biomechanics Group, Botanic Garden, Faculty of Biology, \\ University of Freiburg, Schänzlestrasse 1, 79104 Freiburg, Germany, \\ ${ }^{2}$ FIT, Freiburg Center for Interactive Materials and Bioinspired \\ Technologies, Georges-Köhler-Allee 105, 79110 Freiburg, Germany, \\ ${ }^{3} \mathrm{FMF}$, Freiburg Materials Research Center, Stefan-Meier-Strasse 21, \\ 79104 Freiburg, Germany and ${ }^{4}$ Cluster of Excellence livMatS@ FIT- \\ Freiburg Center for Interactive Materials and Bioinspired \\ Technologies, University of Freiburg, Georges-Köhler-Allee 105, \\ 79110 Freiburg, Germany \\ Email: \\ Venkata A. Surapaneni* - svamarnadh@gmail.com \\ * Corresponding author \\ Keywords: \\ cuticular ridges; insect adhesion; leaf surfaces; ontogeny; polarity; \\ surface replication
}

Beilstein J. Nanotechnol. 2021, 12, 1326-1338. https://doi.org/10.3762/bjnano.12.98

Received: 22 June 2021

Accepted: 10 November 2021

Published: 01 December 2021

This article is part of the thematic issue "Biomimetics on the micro- and nanoscale - The 25th anniversary of the lotus effect".

Associate Editor: K. Koch

(c) 2021 Surapaneni et al.; licensee Beilstein-Institut. License and terms: see end of document.

\begin{abstract}
The plant cuticle is a multifunctional barrier that separates the organs of the plant from the surrounding environment. Cuticular ridges are microscale wrinkle-like cuticular protrusions that occur on many flower and leaf surfaces. These microscopic ridges can help against pest insects by reducing the frictional forces experienced when they walk on the leaves and might also provide mechanical stability to the growing plant organs. Here, we have studied the development of cuticular ridges on adaxial leaf surfaces of the tropical Araceae Schismatoglottis calyptrata. We used polymer replicas of adaxial leaf surfaces at various ontogenetic stages to study the morphological changes occurring on the leaf surfaces. We characterized the replica surfaces by using confocal laser scanning microscopy and commercial surface analysis software. The development of cuticular ridges is polar and the ridge progression occurs basipetally with a specific inclination to the midrib on Schismatoglottis calyptrata leaves. Using Colorado potato beetles as model species, we performed traction experiments on freshly unrolled and adult leaves and found low walking frictional forces of insects on both of these surfaces. The changes in the micro- and macroscale morphology of the leaves should improve our understanding of the way that plants defend themselves against insect herbivores.
\end{abstract}

\section{Introduction}

The plant cuticle is a thin non-cellular membrane that covers most of the above-ground organs of land plants. It is a composite matrix consisting of cutin and cutan as its main components, contains intracuticular waxes, and typically is covered by an outer layer of epicuticular waxes. The cuticle and the underlying epidermal cell wall are linked by a transition region that is 
rich in cellulose, hemicellulose, and pectin [1-5]. The outer peripheral layer of the cuticle may show various microscopic morphological structures such as cuticular ridges, epicuticular wax crystals, trichomes, and hairy structures $[4,6]$. The cuticular structures together with the epidermal cell shape and the cuticle chemistry provide the leaf surface with multiple functions [7]. In particular, cuticular ridges on some leaf surfaces have been found to reduce the frictional forces of insects during walking and may increase the hydrophobicity of the leaf surfaces $[8,9]$. On petals, they might act additionally as diffraction gratings producing structural colors to attract pollinators [1012]. Ridges are relatively robust compared with other cuticular morphologies [8] such as epicuticular wax crystals. They may also provide mechanical stability to the growing organs by possibly avoiding cuticle cracking and maintaining structural integrity during rapid leaf area expansion [13,14].

Recently, a study of 75 different eudicot species has shown that their leaf growth is polar (or direction-dependent) and diverse and has identified four characteristic growth patterns: (1) basipetal, (2) acropetal, (3) diffused, and (4) bidirectional [15]. Such polarity in leaf growth is a result of direction-dependent cell differentiation, maturation, and proliferation processes along or perpendicular to the direction of the midrib [1521]. One aspect that would be interesting to know is whether cuticular structures such as ridges also display such polarity during growth in the proximodistal or mediolateral axes. This is the focus of the present study. Such knowledge will help in understanding the mechanical basis of morphological changes and structural integrity of plant surfaces. Whereas the architecture of the cuticular structures and the associated functionalities have been well studied, detailed analyses concerning growthinduced changes in the morphology of cuticular structures are largely absent. Hong et al. [22] have reported that the cuticular ridges on Arabidopsis thaliana sepals develop basipetally, and that the ridge progression coincides with the growth and maturation of epidermal cells. Recently, Surapaneni et al. [23] have reported that, on the leaves of Hevea brasiliensis trees, the cuticular ridges also have a polarity during development but are characterized by an acropetally directed progression. They have also found that the ridge development coincided with the directional color changes occurring on the leaf surfaces.

Our preliminary microscopic examination and visual observations have shown that such directional color changes also occur on the cuticular ridge containing adaxial leaf surfaces of Schismatoglottis calyptrata (Roxb.) Zoll. \& Moritzi, Ailanthus altissima (Mill.) Swingle and Aesculus parviflora Walter. In $S$. calyptrata, the leaves are rolled in leaf sheaths during bud formation and unroll during maturation, and thus, it is a worth- while plant model to understand the development of cuticular ridges on the leaf surfaces with such varying macromorphology. Therefore, we have chosen $S$. calyptrata as a model plant in this study and tested the presence of polarity in the ridge development on the adaxial leaf surfaces. In addition, we have also tested the walking frictional forces of insects on freshly unrolled and adult adaxial leaf surfaces. S. calyptrata (Araceae) is a monocotyledonous species that has variegated leaves and that is distributed from Southwest China to Vanuatu [24,25]. It grows typically in tropical forest understories, forms stoloniferous (horizontal stems close to the soil surface) colonies, and can grow up to $60 \mathrm{~cm}$ tall. They are usually $15-50 \mathrm{~cm}$ long, variegated with grey-green or yellowish green spots, and form up to six leaves per crown $[25,26]$. In this study, we have used polymer replicas of the $S$. calyptrata leaf surfaces at various ontogenetic stages for morphometric analyses. Polymer replication of the leaf surfaces helps to avoid artifacts arising from leaf dehydration during time-consuming microscopical analyses, especially with regard to the imaging of young leaf surfaces $[7,23]$. By means of confocal microscopy experiments, we demonstrate that polarity in ridge development also occurs on leaves of $S$. calyptrata and that the surface roughness of the leaves increases as the leaves mature. Previous studies have found reduced insect adhesive forces on rough plant surfaces [8,9,23,27-31]. By performing traction experiments using Colorado potato beetles (Leptinotarsa decemlineata) as model insect species, we show that the walking frictional forces of insects are reduced as well on freshly unrolled as on adult leaf surfaces.

\section{Results \\ Leaf ontogeny and replication}

Leaves were in the rolled state at stage 1 ( 5 days from bud formation) and stage 2 (10 days from bud formation). After exponential leaf growth (Supporting Information File 1, Figure S1), the leaves unrolled at stage 3, after 12-26 days from bud appearance. Stage 4 occurred at a leaf age of 22-35 days, when the growth of the leaves as measured from the length of the midrib ceased. The leaf sizes (the leaf sheath to tip length in stages 1 and 2; midrib lengths in stages 3 and 4) varied from $0.5-5 \mathrm{~cm}$ at stage $1,7-10 \mathrm{~cm}$ at stage $2,11-21 \mathrm{~cm}$ at stage 3 , to $15-24 \mathrm{~cm}$ at stage 4 .

The polydimethylsiloxane (PDMS, positive mold) replicas of the leaf surfaces aided the study of the ontogenetic variation in the morphology of the ridges. Some leaf material, but only at stages $2 \mathrm{~A}$ and 3, remained attached to the epoxy (negative mold) replicas during the replication process. However, in contrast to the results from Surapaneni et al. [23] on $H$. brasiliensis leaves, potassium hydroxide $(\mathrm{KOH})$ treatment removed all the plant material from the epoxy surfaces, and 
thus, clean PDMS replicas from all leaf stages could be obtained.

\section{Structure of the cuticle - temporal and spatial changes}

Figure 1 shows $S$. calyptrata leaves at their different ontogenetic stages (Figure 1a) and the corresponding confocal laser scanning microscopy (CLSM) observations (Figure 1b-f) on leaf microstructures. A schematic representation of the leaves and the corresponding locations of smooth and ridged morphologies is provided in Figure 2. The ontogenetic variations in roughness on the $S$. calyptrata leaf surfaces are given as the arithmetic average roughness $(R a)$ versus leaf stage in Figure 3a and as the ridge aspect ratio $(A R)$ versus leaf stage in Figure $3 \mathrm{~b}$.

The roughness values of the leaf replicas revealed significant differences within leaf stages (Kruskall-Wallis, $\chi^{2}$ for $R a=103.24, \chi^{2}$ for $A R=109.24, \mathrm{df}=4, p<0.001, n, \mathrm{~S} 1=20$, $n, \mathrm{~S} 2-\mathrm{S} 4=30$ ). Figure $1 \mathrm{~b}$ and Figure $1 \mathrm{~d}$ demonstrate leaf surfaces with smooth epidermal cells without any cuticular structuring at stages 1 and $2 \mathrm{~B}$, respectively. The presence of a ridgelike structure along some anticlinal fields on the surfaces of the leaves at stage 2B (arrow in Figure 1d) was found. However, the $R a$ and $A R$ of the ridges did not change significantly from
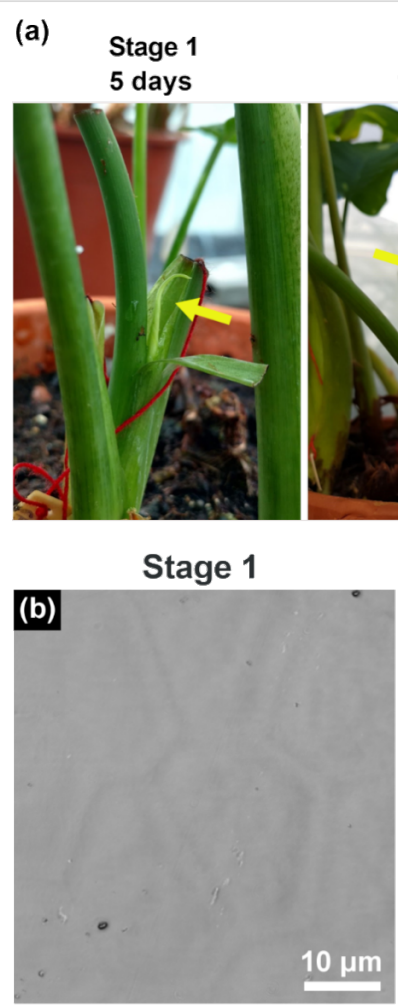

Stage 2 10 days

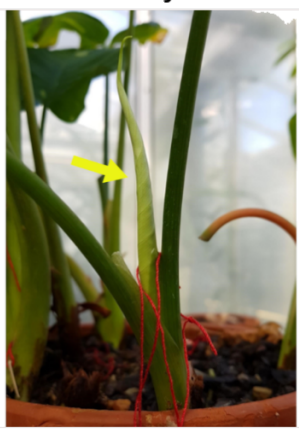

Stage 2A

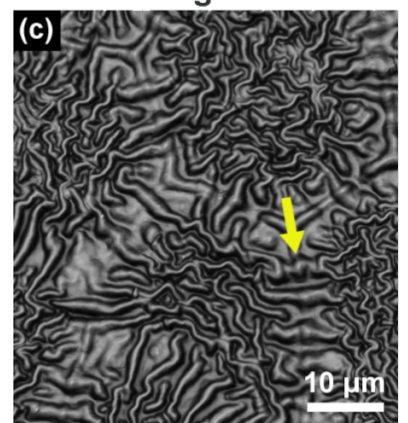

Stage 3 12-26 days
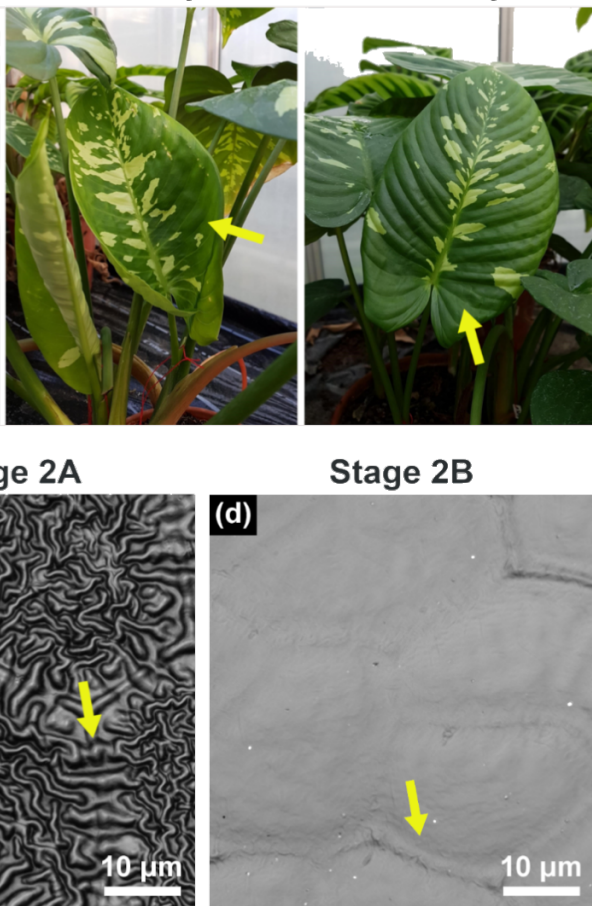
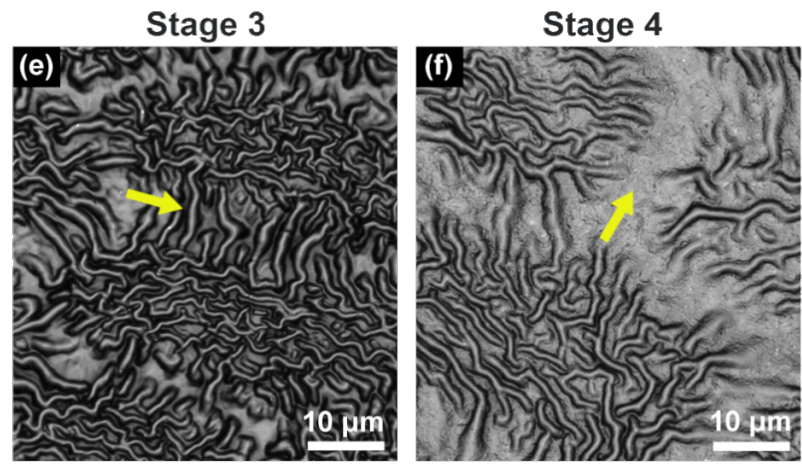

Figure 1: Leaf ontogeny and cuticular ridge development. (a) Leaf development from bud appearance during the various ontogenetic stages in Schismatoglottis calyptrata. (b-f) CLSM images of leaf replica surfaces during the different ontogenetic stages. Leaf surfaces contained smooth cells at stage 1 and stage $2 \mathrm{~B}$, high aspect ratio zig-zag shaped ridges at stages $2 \mathrm{~A}$ and 3 , and less dense and low aspect ratio ridges at stage 4 . Arrows indicate: (a) leaves at the respective stages; (c) and (e) thick and long ridges connecting the peripheries of the adjacent cells; (d) a ridged structure along the anticlinal field; (f) the anticlinal field free of ridges. 

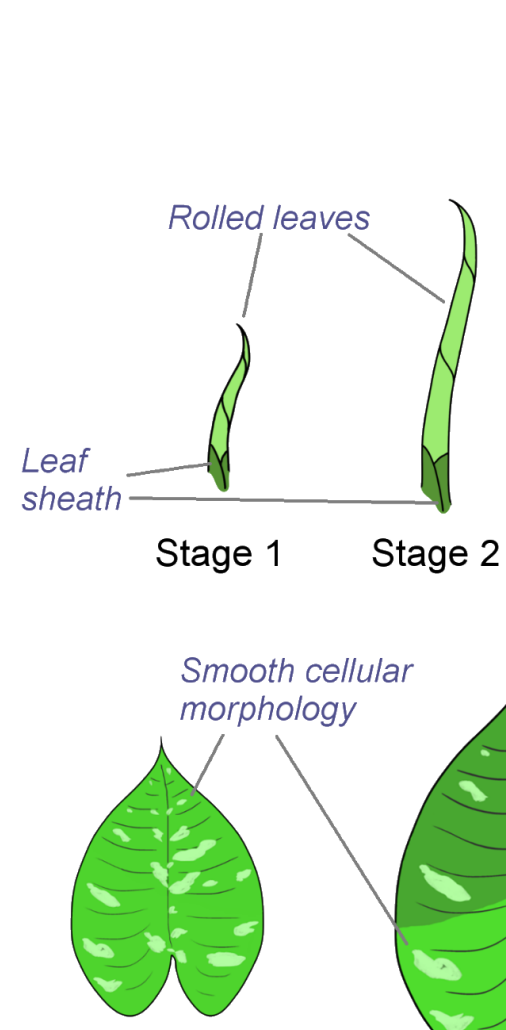

Stage 1 unrolled

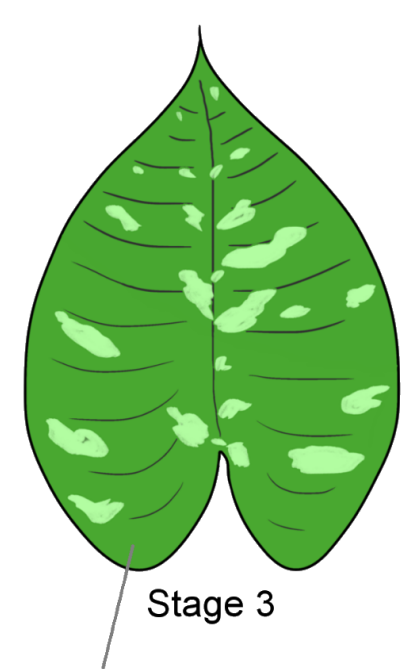

High aspect ratio cuticular ridges

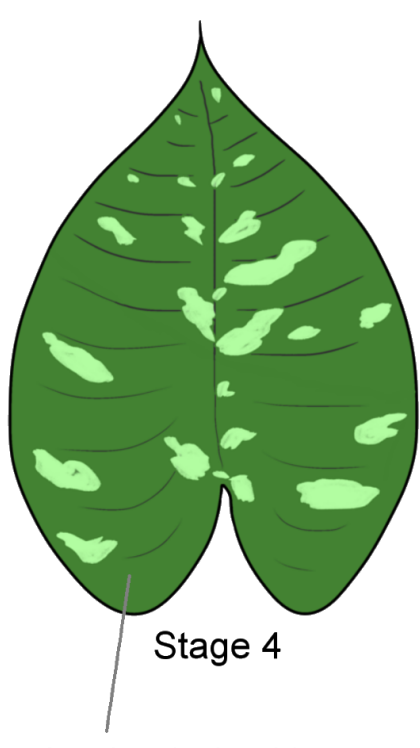

Aged cuticular ridges

Stage $2 \mathrm{~A}$

Stage $2 B$

Figure 2: Schematic representation of leaf growth stages of Schismatoglottis calyptrata and their respective surface microstructures. At stages 1 and 2 , leaves are normally in the rolled position. The schematics show the leaf colors when the leaves were unrolled manually.

stage 1 to stage 2B $(R a: p=1, A R: p=1, n, \mathrm{~S} 1=20, n$, $\mathrm{S} 2 \mathrm{~B}=30$ ). A basipetal progression (apex to base) of the cuticular ridges occurred with the growth of the leaves during stage 2. The morphometric analysis revealed the rapid formation of high aspect ratio cuticular ridges in the region close to the apex (stage 2A, Figure 1c). Accordingly, the $R a$ and $A R$ values increased significantly at stage $2 \mathrm{~A}$ when compared with stage 1 and stage $2 \mathrm{~B}$ ( $R a$ and $A R: P<0.001, n=30)$. At stage 3, the entire surface of the leaves was covered with cuticular ridges as shown in Figure 1e, and no significant difference was observed in $R a$ and $A R$ when compared with those of stage $2 \mathrm{~A}$ (Ra: $P=1, A R: P=1, n=30$ ). At stages $2 \mathrm{~A}$ and 3, additionally, the anticlinal fields were characterized by thick and long ridges that connected the ridge islands on the adjacent cells (arrows in Figure 1c,e). As leaf growth progresses, the cuticular ridges have been reported to disappear on leaf or sepal surfaces $[22,32]$. However, cuticular ridges were still present on $S$. calyptrata leaf surfaces even at stage 4 . Nevertheless, they were characterized by reduced height and increased spacing between the ridges (see Table 1), probably caused by cell growth (Figure 1f). The AR value decreased, but the $R a$ value did not vary significantly when compared with the values at stage 3 ( $R a: p=0.26, A R=0.04, n=30$ ). A comparison of the CLSM recordings of leaf surfaces at all stages (Figure 1b-f) showed that the cells grew unevenly when they reached adult stages. Therefore, with the uneven growth of the cells, the ridges elongated (reduced zig-zag pattern), and the anticlinal fields between the cells became mostly free of cuticular ridges (arrows in Figure 1f). We observed no notable differences in the ridge dimensions between the dark green regions and the yellowish green regions on the variegated leaf surfaces (average of three spots in the dark green region: $R c=0.76 \mu \mathrm{m}, R s m=3.0 \mu \mathrm{m}$, $A R=0.25$; in the yellowish green region: $R c=0.88 \mu \mathrm{m}$, $R s m=3.03 \mu \mathrm{m}, A R=0.29)$.

The mean values of the roughness parameters are shown in Table 1. These values of mean height $(R c)$ and spacing (Rsm) of the ridges at the intermediate stages $2 \mathrm{~A}$ and stage 3 are more than twice the values in the corresponding stages $2 \mathrm{~B}$ and 3 (stage $2 \mathrm{~B}: R c=0.36 \mu \mathrm{m}, R s m=1.10 \mu \mathrm{m}$; stage 3 : $R c=0.42 \mu \mathrm{m}, R s m=1.13 \mu \mathrm{m})$ on the leaves of the $H$. brasiliensis tree [23]. Surapaneni et al. [23] reported that 

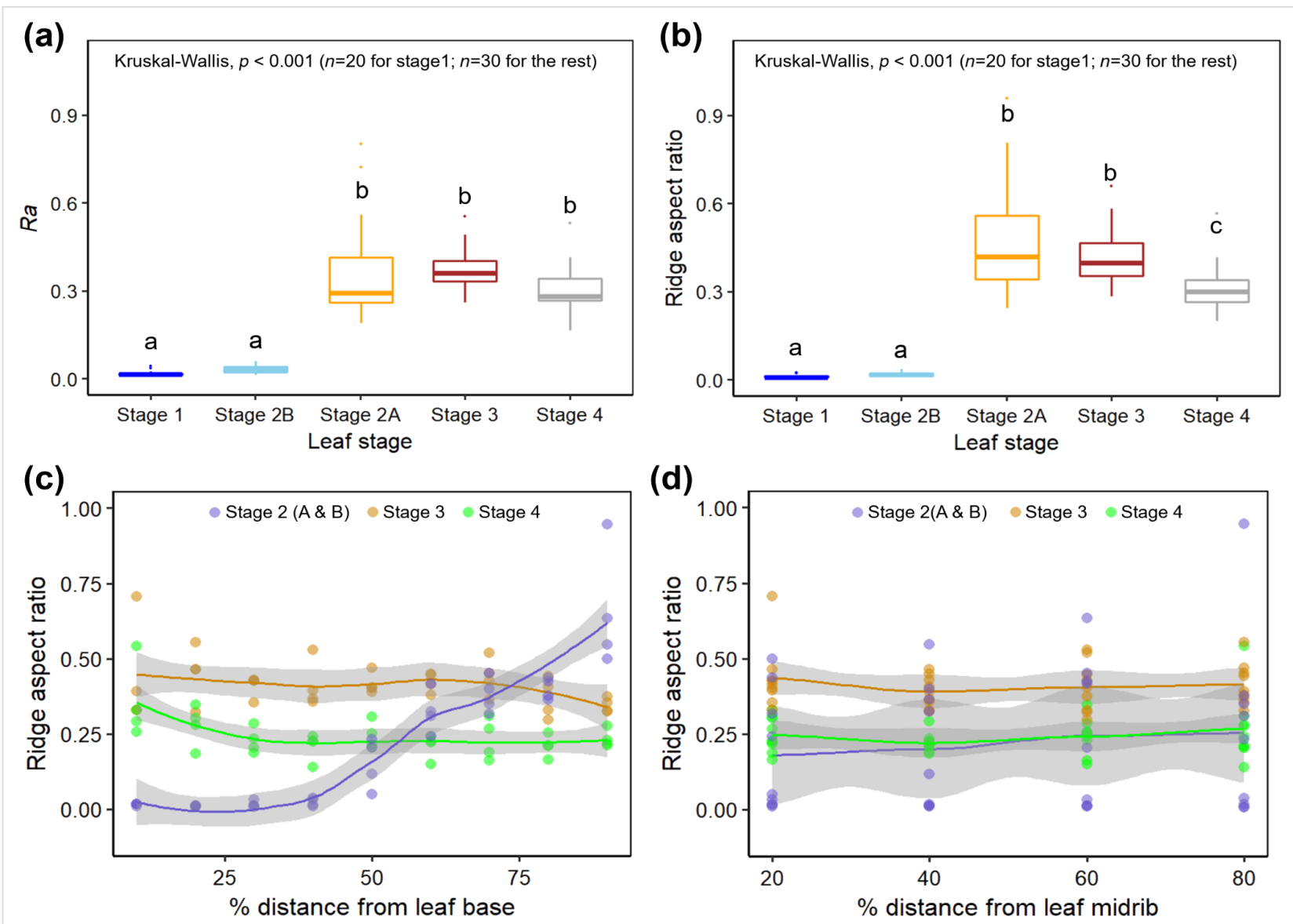

Figure 3: The plots show (a) the variation in the arithmetic average roughness $(R a)$ of the leaf surfaces with different growth stages, (b) the variation in the ridge aspect ratio with different leaf growth stages, (c) the spatial variation of the ridge aspect ratio along the direction of the midrib as percentage distance from the base of the leaf, and (d) the variation of ridge aspect ratio perpendicular to the direction of the midrib as percentage distance from the midrib. The gray shading around the lines represents the $95 \%$ confidence interval.

Table 1: Mean values of roughness parameters of cuticular ridges on leaf surfaces of Schismatoglottis calyptrata at stages $2 \mathrm{~A}, 3$, and 4 .

\begin{tabular}{lllll} 
Stage & $R a$ in $\mu \mathrm{m}$ & $R c$ in $\mu \mathrm{m}$ & $R s m$ in $\mu \mathrm{m}$ & $A R=R c / R s m$ \\
\hline stage 2A & 0.36 & 1.03 & 2.16 & 0.48 \\
stage 3 & 0.37 & 1.06 & 2.61 & 0.41 \\
stage 4 & 0.30 & 0.88 & 2.90 & 0.31
\end{tabular}

$\mathrm{KOH}$ treatment was unsuccessful in removing plant material from the negative epoxy replicas. In the present study, the higher roughness (particularly, mean spacing) values on $S$. calyptrata leaf surfaces might have resulted in the easy of removal of plant material from the epoxy negatives.

Figure $3 \mathrm{c}$ and Figure $3 \mathrm{~d}$ show the variation in the aspect ratio values in the proximodistal axis and the variation in the aspect ratio values along the mediolateral axis, respectively. The data were smoothened within stages by using the loess (local linear smoothing) method. We found an almost linear increase in the ridge aspect ratio beyond $40 \%$ from the base of leaves at stage 2 . The area above $40 \%$ essentially represents stage $2 \mathrm{~A}$ when the ridges start developing rapidly. At stage 3, the overall ridge aspect ratio reduced and showed further reduction beyond $70 \%$ from the leaf base. During stage 4, the aspect ratio continued to decrease slightly, until approximately $30 \%$ from the leaf base and remained constant thereafter. The aspect ratio was mostly constant in the direction perpendicular to the midrib for stages 2, 3, and 4 (Figure 3d).

The ridge progression on S. calyptrata leaves did not occur parallel to the proximodistal axis but at a specific inclination to the midrib (Figure 2). This could also be clearly observed from the difference in light reflection from the epoxy replicas. Figure 4 shows a typical epoxy replica of a leaf at stage 2 displaying the inclined ridge progression line. CLSM analysis showed that the surface of the transparent region of the epoxy replica corresponded to that of smooth unstructured cells, whereas the surface of the opaque region was covered with dense cuticular ridges. 


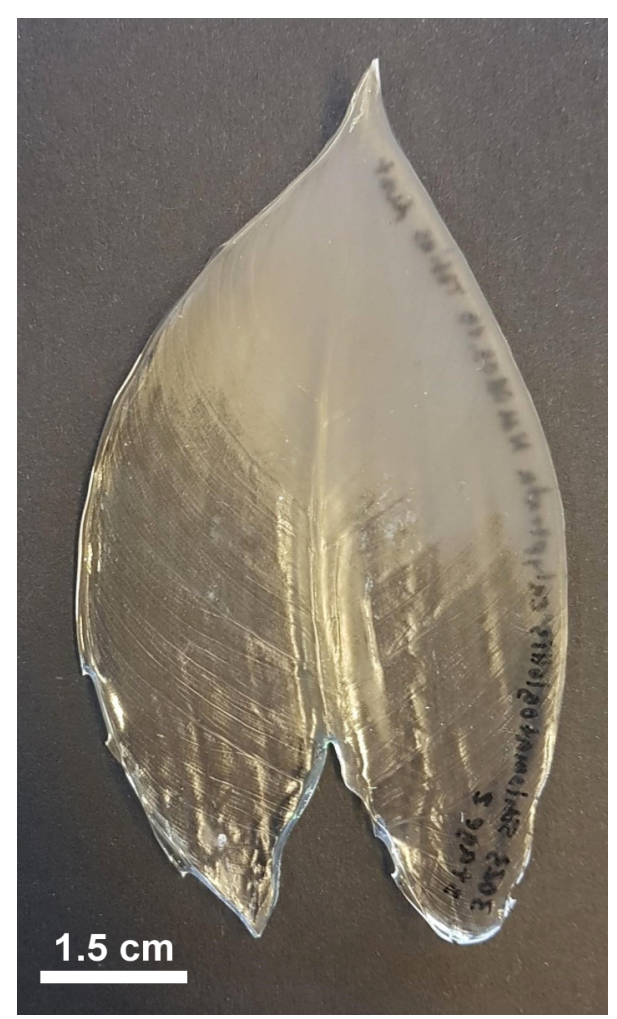

Figure 4: A typical epoxy replica of the surface of a leaf at growth stage 2 having a ridge progression inclined with the midrib. The transparent region represents stage $2 \mathrm{~B}$ and contains smooth cells. The opaque region represents stage $2 \mathrm{~A}$ and contains densely arranged high aspect ratio cuticular ridges. The inclined ridge progression might be the result of uneven exposure of the leaves to the outside environment.

Analysis of individual epidermal cells demonstrated the change of size and orientation of the cells and the ridge islands during the ontogeny (Figure 5). Figure 5a demonstrates the demarcation of ridge islands and the periphery. The variation in the area of ridge islands and the epidermal cells during ontogeny are plotted as boxplots in Figure 5b. There are significant differences in the cell size (Kruskall-Wallis, $\chi^{2}=51.35$, $\mathrm{df}=4$, $p<0.001, n=12$ ) and ridge island size (Kruskall-Wallis, $\chi^{2}=25.18, \mathrm{df}=2, p<0.001, n=12$ ) during ontogeny. Pairwise analysis of cell area showed no significant differences between adjacent stages (Figure $5 \mathrm{~b}$ ). The cell size is, however, significantly different between stages 1 and $3(p<0.001$, $n=12)$, stages 1 and $4(p<0.001, n=12)$, stages $2 \mathrm{~A}$ and 4 $(p<0.01, n=12)$, stages $2 \mathrm{~B}$ and $3(p<0.01, n=12)$ and stages $2 \mathrm{~B}$ and $4(p<0.001, n=12)$. Note that the cell size data are normally distributed and the variances are homogenous. Since the data were collected from the same leaf replica, it was assumed that the data were not independent. If the data were assumed to be independent, ANOVA analysis showed significant differences $(p<0.001, n=12)$ in cell size between all the stages except between stages 1 and 2B $(p<0.80, n=12)$. The size of ridge islands differes significantly between adjacent leaf stages $(p<0.01$ between stages $2 \mathrm{~A}$ and 3 and stages 3 and 4 , and $p<0.001$ between stages $2 \mathrm{~A}$ and $4 ; n=12$ ). Figure $5 \mathrm{~b}$ also shows that the difference between the median values of cell and ridge island areas increases with leaf growth, demonstrating the increase in the area of the periphery or the anticlinal region with cell growth. The variation in the density of cells and ridge islands (as number of cells per square millimeter and ridge islands per square millimeter, respectively) with leaf growth is shown in Table 2. The density of the ridge islands is almost twice as that of the cells in all stages of ridge progression and growth. Figure $5 \mathrm{c}$ shows the frequency distribution of the orientation of the long axes of cells and ridge islands with respect to the midrib of the leaf at all growth stages. Typical examples of data on the orientation of ridges in the ridge islands and the periphery regions for the different growth stages are shown in Supporting Information File 2. The analysis showed that, in the periphery region the ridges were radially oriented relative to the centre of the ridge island during all stages of ridge progression and growth. In the ridge islands, however, the ridges had a complex zig-zag-like orientation during stage 2A. Similarly, during stage 3 , the ridges were mostly oriented in a zig-zag manner, although on some cells longitudinal alignment of the ridges along the long axes of the cells was observed. During stage 4, the ridge orientation was mostly longitudinally oriented along the long axes of the cells.

\section{Insect traction forces}

The maximum insect traction forces on freshly unrolled (stage 3) and adult (stage 4) $S$. calyptrata leaves differed significantly from those on glass (Kruskal-Wallis, $p<0.01, n=7$ ). Figure 6 shows the variation in the traction forces of insects on glass and leaf surfaces. When compared with the forces on glass $\left(F_{\text {median }}=11.79 \mathrm{mN}\right)$, the traction forces of insects are reduced significantly on stage $3\left(F_{\text {median }}=2.02 \mathrm{mN}, p<0.05, n=7\right)$ and stage $4\left(F_{\text {median }}=1.56 \mathrm{mN}, p<0.01, n=7\right)$ leaves. However, the forces did not differ significantly between stage 3 and stage 4 leaves ( $p=1.00, n=7)$.

\section{Discussion}

In this study, we have demonstrated that the morphology of the cuticular ridges on the adaxial side of $S$. calyptrata leaves changes significantly during leaf ontogeny. Similar to $H$. brasiliensis [23], the ontogenetic changes on S. calyptrata leaf surfaces revealed three distinct levels of cuticular morphology that coincided with the color changes on the leaf surfaces, albeit with few differences. Supporting Information File 1, Figure S2 shows the comparison of these distinct morphological levels on $H$. brasiliensis and $S$. calyptrata leaf surfaces. The first level is characterized by smooth epidermal cells with no 
(a)

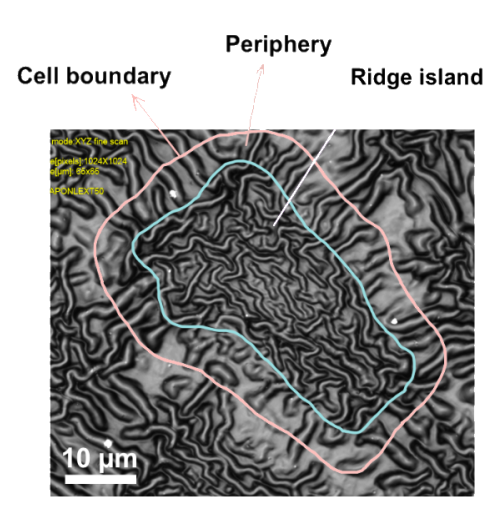

(b)

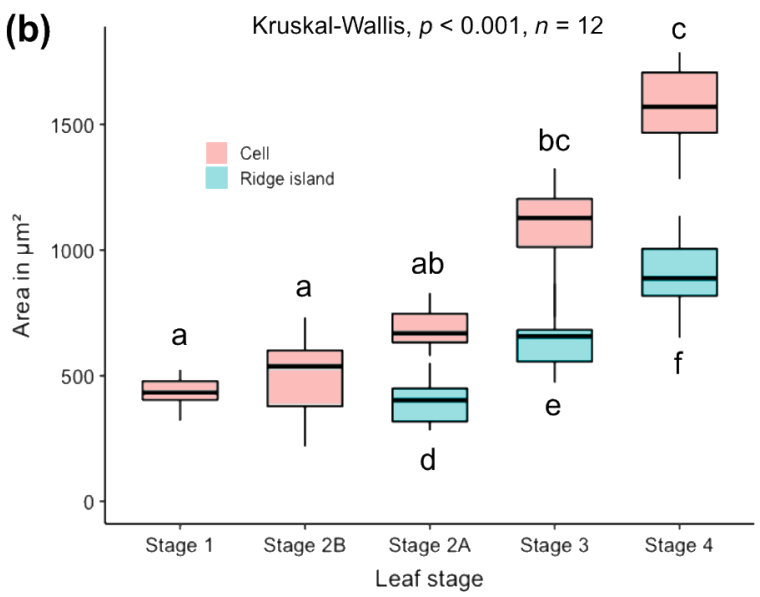

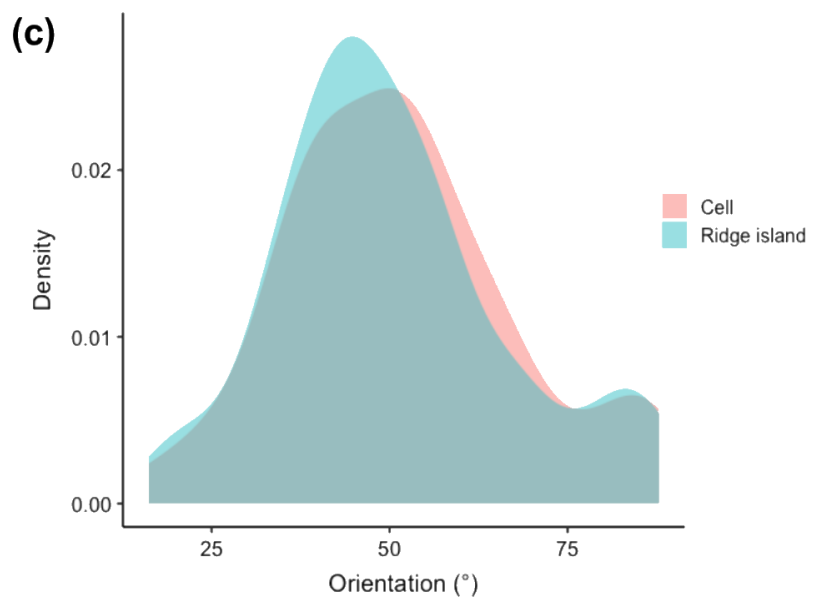

Figure 5: Cell size and orientation. (a) The outlines show the area of the epidermal cell as the sum of areas of ridge island, where the ridges are arranged in a nearly zig-zag pattern, and periphery, where the ridges are arranged nearly radially with respect to the center of the ridge island, (b) the boxplots show the increase in the area of cells (in pink) and ridge islands (in blue) with leaf growth, and (c) shows frequency density plots of orientations of the long axes of cells (in pink) and ridge islands (in blue) with respect to the midrib of the leaf.

Table 2: The variation in the density of cells and ridge islands (as number of cells per square millimeter) with leaf growth.

\begin{tabular}{lll} 
Stage & Density of ridge islands per square millimeter $(r)$ & Density of cells per square millimeter $(c)$ \\
\hline stage 1 & & \\
stage 2A & 2482.52 & 2322.41 \\
stage 2B & & 1423.08 \\
stage 3 & 1609.37 & 2000.21 \\
stage 4 & 1115.81 & 892.44 \\
& & 626.60
\end{tabular}

superimposed cuticular structures, which occurred from the bud appearance until stage 1 in both species, and further in stage $2 \mathrm{~A}$ (region towards apex) in H. brasiliensis (Supporting Information File 1, Figure S2a) and stage 2B (region towards base) in S. calyptrata (Supporting Information File 1, Figure S2d). The second level pertains to densely arranged high aspect ratio ridges oriented in a zig-zag manner, which developed acropetally from stages $2 \mathrm{~B}$ and 3 in $H$. brasiliensis (Supporting Information File 1, Figure $\mathrm{S} 2 \mathrm{~b}$ ) and basipetally from stages $2 \mathrm{~A}$ and 3 in S. calyptrata (Supporting Information File 1, Figure $\mathrm{S} 2 \mathrm{e})$. In this level, the ridges on S. calyptrata leaf surfaces were thicker and more loosely packed (also see Results section) with larger mean spacing between the ridges when compared with those on $\mathrm{H}$. brasiliensis leaves. These morphological dissimilarities of the cuticular ridges might have contributed to the differences in plant material separability from the negative molds in both species. In addition to possible chemical interactions between leaf material and epoxy during replication, the mean 


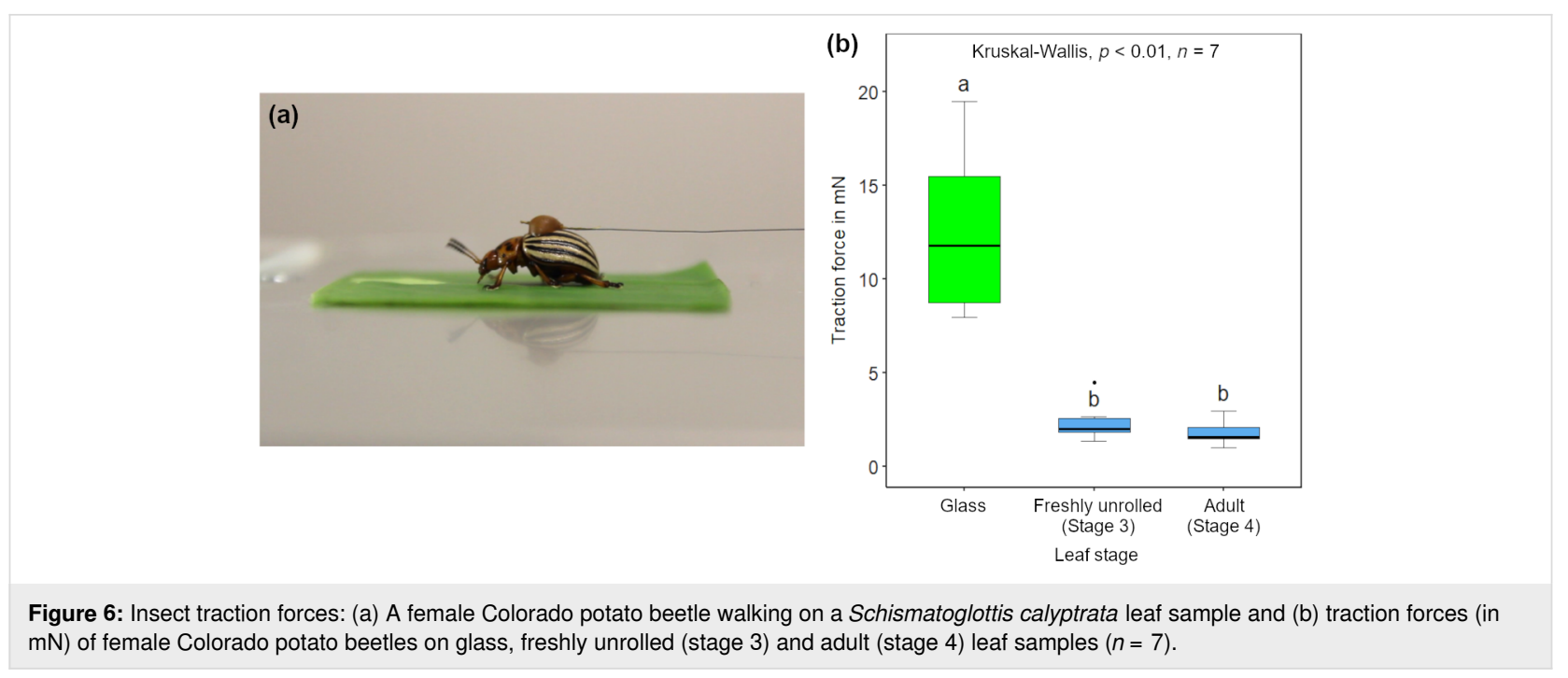

spacing between the ridges might be a factor enabling the efficient separation of plant material from the epoxy negative molds during polymer replication. The third level is characterized by aged and uniformly aligned low aspect ratio ridges in a labyrinth-type arrangement (at stages 4 and 5) in H. brasiliensis (Supporting Information File 1, Figure S2c), and low aspect ratio, thick, elongated and spaced ridges with smooth anticlinal fields (at stage 4) in S. calyptrata (Supporting Information File 1, Figure S2f). In this level, in S. calyptrata leaf surfaces, the ridges also have predominantly longitudinal orientation representing stretching of the ridges during cell expansion. From the second level to the third level, the ridge islands and the anticlinal fields undergo growth-induced expansion resulting in the observed morphological changes and alignment of ridges. Hong et al. [22] also reported that the densely arranged cuticular ridges on wild-type Arabidopsis sepals form at an intermediate stage with a basipetal progression and that the density of the ridges reduces as the cells mature. They have also shown that, on Arabidopsis sepals, the cells beneath the ridges mature at the same time as ridges form over the cells. Assuming that this is also the case in S. calyptrata leaves, the levels of ridge formation, development, and morphology appear to follow a general pattern based on the underlying cellular processes in both leaves and sepals.

In contrast to $H$. brasiliensis leaves and Arabidopsis sepals, the ridge progression on S. calyptrata leaves occurs with a specific inclination to the midrib. Notably, S. calyptrata leaves remain rolled-up from bud formation until stage 3 . Moreover, when the ridges start to develop (stage $2 \mathrm{~A}$, in the region close to the leaf apex), the region close to the base of the leaves still lies within the leaf sheath, and the leaf margin over the rolled leaf covers the leaf in an inclined fashion (intuitive from a simple rolled paper experiment). The rolling of the leaves during the initial developmental stages might be an evolutionary trait because of various abiotic factors such as water stress, temperature, and excess radiation and/or might represent a defense mechanism against, for example, insects or viruses [33-35]. When the leaves are rolled, the intensity of light reaching each underlying layer of the rolled-up leaf and the transpiration properties within each layer will be different. Such unevenness in the exposure of the leaf to the external environment might result in the inclined ridge progression on the $S$. calyptrata leaves. Also, the presence of ridges on the leaf surfaces might reduce friction, thereby, avoiding damage between the delicate rolled leaf layers during unrolling and growth.

Previous studies on cuticular ridge development [22,23] and our observations of $S$. calyptrata leaves as presented in this study also establish that the formation and the development of cuticular ridges on plant leaf and sepal surfaces display polarity in various plant species, probably correlated with the polarity in leaf and sepal growth. Whereas cuticular ridge development is known to have polarity, we need to understand the mechanical effects required for such development. During young leaf stages, the thickness of the cuticle is usually low, and the growth of the leaves is, in general, accompanied by the thickening of the cuticle, because of the addition of cuticular material [3]. Martens [36] predicted that the overproduction of cuticle material induces the formation of cuticular ridges, a predication supported by a recent model [37]. In environments with high temperatures, low humidity, and high light intensity, plants are known to develop thicker and (more) waxy cuticles [38-40]. Therefore, as described in the previous section, the ridge development on the leaves (Figure 2 and Figure 4) might depend upon the way that leaves are covered and protected (by being rolled) during growth and their interaction with the external environment. 
Mechanically, when the strain in the cuticle (induced by the simultaneous isotropic production of the cuticle and anisotropic expansion of the underlying cells) increases beyond a critical strain value, ridges start to develop $[37,41,42]$. Moreover, the amount of polysaccharide and cutin components present in the cuticle probably influences the stiffness and elastic behavior of the cuticle-cell wall interface [43] and certainly affects ridge formation. The thickened cuticle provides structural support to the growing epidermal cells [14], and the ridges might help in maintaining the structural integrity of the cuticle by avoiding cracking during rapid leaf expansion. The way that the amount and arrangement of the cuticular components vary during the cellular growth processes throughout ontogeny might determine the differences in cuticular morphology among the various plant species or the means by which polarity is established in cuticular (ridge) development in a given species. Vice versa, the variation in the morphology of the ridges and the underlying mechanics should enable inferences to be made regarding the underlying structure of the cuticle-cell wall interface. A better understanding of these processes might also provide insights for bioinspired growth or swelling-induced microstructures for technical applications [44].

The morphological changes in the cuticular structure of plant leaves during ontogeny have been demonstrated to influence insect attachment [23]. Our experiments showed reduced traction forces of the model insects (female L. decemlineata, Coleoptera) on freshly unrolled and adult $S$. calyptrata adaxial leaf surfaces. The reduction in the traction forces of the beetles was almost $83 \%$ on the freshly unrolled leaf and almost $87 \%$ on the adult leaf, when compared with those on glass. Earlier studies have found similarly large reduction in the traction forces of Colorado potato beetles on leaves with cuticular ridges and their replicas when compared with those on glass [8,23]. Therefore, from the point of leaf unrolling until adult leaf stages of $S$. calyptrata, the cuticular structure may influence the attachment and, thus, the activity of herbivores or pollinators (associated with the order, Coleoptera [45]). During young stages, however, the $S$. calyptrata leaves remain rolled-up, a type of macroscale morphology that might also reduce herbivory [34].

\section{Conclusion}

CLSM measurements of PDMS replicas of Schismatoglottis calyptrata leaves have shown that the cuticular ridges display pronounced polarity and morphologically distinct levels during development. We have found smooth cellular surfaces on young leaf surfaces and ridges developing basipetally on leaf surfaces at an intermediate leaf stage. As soon as ridge development starts, the ridge aspect ratio immediately increases almost linearly on the same leaf in the direction parallel to the midrib.
The aspect ratio, however, is significantly reduced on adult (aged) leaf surfaces, with the anticlinal fields being almost free of ridges. The variations in the morphology of cuticular ridges shown in the present study and from previous studies suggest a general (three-level) pattern of ridge development in various plant species and organs. We have also found that ridge progression occurs at an inclination to the proximodistal axis on Schismatoglottis calyptrata leaves, possibly a result of leaf rolling and nonuniform exposure to the environment during early leaf stages. Our results can be extrapolated to the mechanistic basis of cuticular structure (ridge) development and might, thus, be of interest with regard to bioinspired applications. While the macroscale morphology of the leaves is expected to influence insect attachment during young leaf stages, the cuticular microstructuring on the leaf surfaces influences insect attachment during mature leaf stages.

\section{Experimental \\ Leaf collection and ontogenetic stages}

$S$. calyptrata plants (potted plant $<0.5 \mathrm{~m}$ height) were cultivated in the glass houses of the Botanic Garden of the University of Freiburg, Germany. The average temperature and average relative humidity in the glass houses were $22.6 \pm 2.6^{\circ} \mathrm{C}$ and $73.5 \pm 11.0 \%$, respectively. Voucher specimens (FB 15013) of the leaves are deposited in the herbarium of Freiburg, University of Freiburg, Germany. The leaf growth was monitored from bud to adult stages. Initial trial experiments by using a confocal laser scanning microscope helped in the classification of the growth stages, which is based on the microstructural morphology of the adaxial leaf surfaces and leaf age. In total, four ontogenetic stages were defined. Stage 1 leaves had smooth epidermal cells with no cuticular structuring. As the young S. calyptrata leaves were still rolled-up at this stage, the ontogenetic stage was defined based on an arbitrarily chosen leaf age, namely five days from bud formation. Stage 2 leaves had cuticular ridges covering half $(50 \pm 10 \%)$ of the leaf surface. This was subdivided into stage $2 \mathrm{~A}$ representing the area toward the apex of the leaves and stage $2 \mathrm{~B}$ representing the area toward the base of the leaves. Since stage 2 leaves also remained in a rolled-up state, we conducted initial trial experiments to estimate the age of the leaves (after 10 days from bud formation) and collected the leaves at this age. The length of the leaves at stages 1 and 2 was considered to be the length from the end of the leaf sheath to the tip of the leaf. The leaves unrolled at stage 3. At this stage, the entire surfaces were covered with cuticular ridges. Stage 4 leaves were adult leaves the growth of which (as deduced from the length of the midrib) was completed.

\section{Surface replication and characterization}

Replication of the leaf surface was carried out using a two-step molding approach (Epoxy-PDMS) as described in Kumar et al. 
[46] and Surapaneni et al. [23], except that the entire adaxial leaf surfaces of $S$. calyptrata (leaf area: $15-293 \mathrm{~cm}^{2}$ ) were replicated in our study. The leaves of S. calyptrata at stages 1 and 2 were un-rolled gently before replication, and all the leaves were attached to a clean flat plate by using double-sided adhesive tape (Tesa SE, Norderstedt, Germany) with the adaxial side of the leaves facing upward. The replication process was started within $10 \mathrm{~min}$ after the leaves were cut. Epoxy (Epoxy Resin L \& Hardener S, Toolcraft, Conrad Electronic SE, Hirschau, Germany; resin to hardener mixing ratio of 10:4.8) negative molds were then obtained from the leaf (master) surfaces. After the epoxy molds were cured, polydimethylsiloxane (PDMS, Bluesil ESA 7250 A \& B kit, Bluestar Silicones GmbH, Leverkusen, Germany; weight ratio of 10:1) positive molds dyed in red were obtained from the negative molds and allowed to cure. A detailed explanation of the replication process is given in Kumar et al. [46] and Surapaneni et al. [23], and is shown schematically in Figure $7 \mathrm{a}$ and Figure $7 \mathrm{~b}$. A total of three leaves in stages 2, 3 and 4, respectively, and two leaves in stage 1 were replicated.

The replicas of freshly cut leaves at the different ontogenetic stages were characterized using a confocal laser scanning microscope (CLSM, Olympus LEXT OLS4000, 405 nm laser, Olympus Corporation, Tokyo, Japan). To assess the statistical differences in ridge morphology on the leaf surfaces of S. calyptrata during ontogeny, ten different spots/areas $(65 \times 65$ $\mu \mathrm{m})$ on both sides of the midrib of each leaf replica were recorded. In order to study the spatial variation in ridge morphology, single leaf replicas from stages 2 (2A and 2B together), 3 , and 4 were tested, and a total of 36 spots $(130 \times 130 \mu \mathrm{m})$ on the left side of the midrib of the leaves were recorded. These spots lay at the intersections of four equal divisions parallel to the midrib and nine equal divisions perpendicular to the midrib of the leaves. The distances from the midrib at each vertical division were measured to obtain the divisions in the parallel direction (Supporting Information File 1, Figure S3). Commercial

(a)

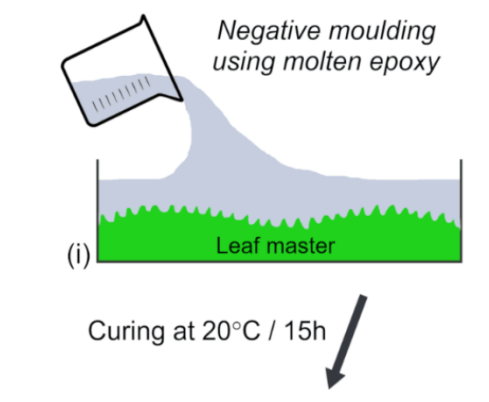

Positive replica demoulding

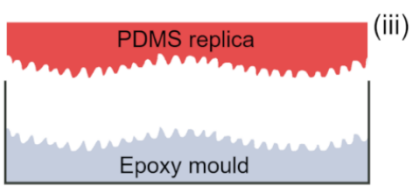

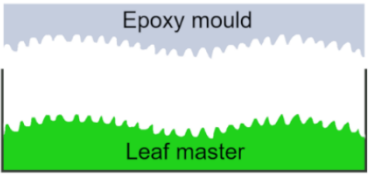

Negative replica demoulding

(b)

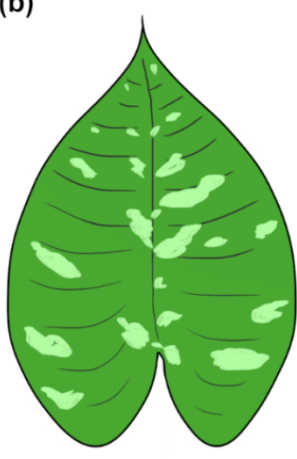

Original leaf (i - master)

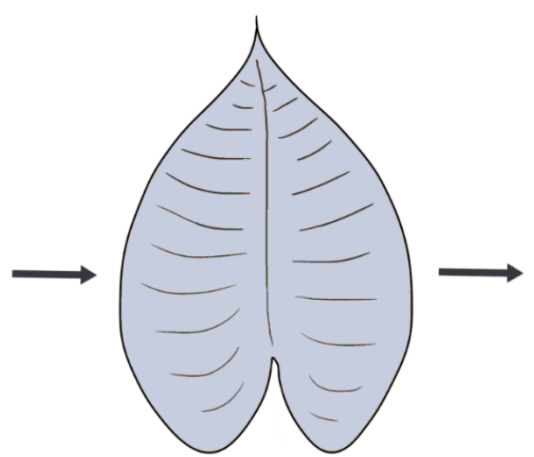

Epoxy mould (ii - negative)
Oven curing at $60^{\circ} \mathrm{C} / 4 \mathrm{~h}$

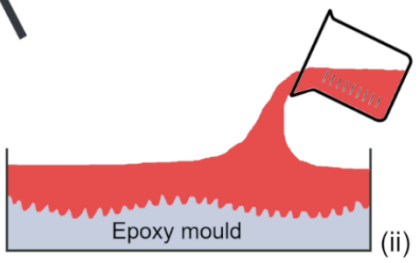

Positive moulding using molten PDMS and red dye

Figure 7: Schematic representation of (a) the replication process of Schismatoglottis calyptrata leaf surfaces and (b) original, epoxy negative and PDMS positive replicas. The leaves at stages 1 and 2 were unrolled for replication and the adaxial side of the leaves at all stages were replicated. 
surface analysis software (Mountains Map Premium version 7.4, Digital Surf SARL, Besançon, France) was used to analyze the CLSM measurements. After the filtering of median noise, zig-zag profile lines of at least $200 \mu \mathrm{m}$ in length were taken on the topographic layer of each spot. A standard Gaussian filter (8 $\mu \mathrm{m})$ was applied to the profiles in order to separate waviness and roughness. In order to compare the variation in the ridge morphology during growth, we calculated standard line roughness parameters, namely $R c$ (mean height), Rsm (mean spacing), $R a$ (arithmetic mean height) [47], and the aspect ratio of the ridges defined as $A R=R c / R s m$.

In addition, we selected single epidermal cells within the spots, and on each cell, we differentiated between "ridge island" as the central region with zig-zag or longitudinal arrangement of ridges (i.e., ridges not radially arranged) and "periphery" as the transition zone between the ridge island and the anticlinal field, featuring ridges that are radially oriented with respect to the cell center. The center of the anticlinal field was used to demarcate the adjacent cells. A total of twelve epidermal cells were analysed within each ontogenetic stage. We used ImageJ software (FIJI, version 1.53f51) to assess the ontogenetic differences in size and orientation of the ridge islands and the epidermal cells (ridge island + periphery, also see Figure 5a). The directionality plugin (version 2.3.0) in ImageJ software was used to analyse the orientation of ridges in the ridge island and the periphery at different growth stages.

\section{Insect traction experiments}

Insect walking frictional forces were measured on a freshly unrolled (stage 3) and an adult (stage 4) S. calyptrata leaf and were compared with the forces on a clean glass slide. The glass slide was cleaned with acetone followed by isopropyl alcohol before performing the traction experiments. For these experiments, female Colorado potato beetles (Leptinotarsa decemlineata, Coleoptera: Chrysomelidae) with hairy tarsal attachment system were used as model insect species. The beetles were collected from an organically farmed potato field in Kirchzarten area near Freiburg, Germany, kept in a terrarium and were fed with potato leaves. The lighting conditions were fixed at a day-night regime of 16L:8D by using a lamp (Osram Lumilux Daylight $860,58 \mathrm{~W})$. Insect traction experiments were performed with a total of seven beetles as described in Prüm et al [8] and Surapaneni and co-workers [23]. A highly sensitive force transducer (FORT 25, force range: $0-0.25 \mathrm{~N}$, World Precision Instruments Inc., Sarasota, USA) was used to measure maximum walking frictional forces of insects on the leaf surfaces. The elytra of each beetle was attached to the force transducer using a human hair by using a small drop of molten beeswax. The insects were allowed to walk actively for at least 2 min on the experimental samples and the forces were re- corded on a computer. Only data from walking in a straight line with less than $\pm 2^{\circ}$ variation were analysed. Within each measurement, the median of the 15 highest local maxima with a minimum interval of $3 \mathrm{~s}$ between neighbouring force peaks was extracted. Supporting Information File 3 shows a potato beetle walking on the leaf surface. The average mass of the beetles was $0.17 \mathrm{~g}$. The experiments were conducted under an average temperature of $23.8 \pm 0.4{ }^{\circ} \mathrm{C}$ and humidity of $41.5 \pm 2.1 \% \mathrm{RH}$.

\section{Statistics}

The roughness, traction force and cell size data were analyzed using Kruskal-Wallis test followed by pairwise multiple comparisons using Dunn's test adjusted with the Bonferroni correction. All statistical tests were performed using $R$ software environment version 3.6.1 [48]. The experimental data (the raw data and the code) for this study is publicly available on https:// freidok.uni-freiburg.de/data/193850 [49].

\section{Supporting Information}

\section{Supporting Information File 1}

Additional figures.

[https://www.beilstein-journals.org/bjnano/content/ supplementary/2190-4286-12-98-S1.pdf]

\section{Supporting Information File 2}

Orientation of ridges in ridge islands and periphery.

The orientation data was collected from the ridge islands and the periphery of a cell using the directionality plugin of the ImageJ software. The data shows typical variation in the ridge orientation (angle with horizontal) at different growth stages.

[https://www.beilstein-journals.org/bjnano/content/ supplementary/2190-4286-12-98-S2.pdf]

\section{Supporting Information File 3}

Colorado potato beetle (Leptinotarsa decemlineata) walking on a Schismatoglottis leaf sample.

[https://www.beilstein-journals.org/bjnano/content/ supplementary/2190-4286-12-98-S3.mp4]

\section{Acknowledgements}

We thank the gardeners of the Botanic Garden, University of Freiburg, for cultivating the $S$. calyptrata plants.

\section{Funding}

This work was supported by Marie Skłodowska-Curie grant (grant agreement No. 722842, ITN Plant-inspired Materials and Surfaces-PlaMatSu) under the European Union's Horizon 2020 
research and innovation program. T.S. and V.A.S. acknowledge additional funding by the Deutsche Forschungsgemeinschaft (DFG, German Research Foundation) under Germany's Excellence Strategy - EXC-2193/1 - 390951807.

\section{Author Contributions}

M.T. and T.S. designed and supervised the study. Data collection, data assessment, and statistical analyses were carried out jointly by T.A. and V.A.S. Data evaluation and the discussion of results was a joint effort by all authors (V.A.S., T.A., T.S., and M.T.). V.A.S. contributed to the first draft of the manuscript, and T.S. and M.T. improved further versions. All authors gave final approval for publication.

\section{ORCID ${ }^{\circledR}$ iDs}

Venkata A. Surapaneni - https://orcid.org/0000-0002-6241-9048 Thomas Speck - https://orcid.org/0000-0002-2245-2636 Marc Thielen - https://orcid.org/0000-0002-7773-6724

\section{References}

1. Holloway, P. J. Structure and histochemistry of plant cuticular membranes: an overview. In The Plant Cuticle; Cutler, D. F.; Alvin, K. L.; Price, C. E., Eds.; Academic Press: London, U.K., 1982; pp 1-32.

2. Kerstiens, G. Plant Cuticles: An Integrated Functional Approach; Environmental plant biology series; BIOS Scientif. Publ.: Oxford, 1996.

3. Jeffree, C. E. The fine structure of the plant cuticle. In Biology of the plant cuticle; Riederer, M.; Müller, C., Eds.; Annual plant reviews, Vol. 23; Blackwell Publishing: Oxford, United Kingdom, 2006; pp 11-125. doi:10.1002/9780470988718.ch2

4. Koch, K.; Bhushan, B.; Barthlott, W. Soft Matter 2008, 4, 1943-1963. doi:10.1039/b804854a

5. Yeats, T. H.; Rose, J. K. C. Plant Physiol. 2013, 163, 5-20. doi:10.1104/pp.113.222737

6. Barthlott, W.; Ehler, N. Raster-Elektronenmikroskopie der Epidermis-Oberflächen von Spermatophyten; Tropische und subtropische Pflanzenwelt 19; Akademie der Wissenschaften und der Literatur Mainz. F. Steiner Verlag [in Komm.]: Wiesbaden, 1977.

7. Kumar, C.; Palacios, A.; Surapaneni, V. A.; Bold, G.; Thielen, M.; Licht, E.; Higham, T. E.; Speck, T.; Le Houérou, V. Philos. Trans. R. Soc., A 2019, 377, 20180265. doi:10.1098/rsta.2018.0265

8. Prüm, B.; Seidel, R.; Bohn, H. F.; Speck, T. J. R. Soc., Interface 2012, 9, 127-135. doi:10.1098/rsif.2011.0202

9. Prüm, B.; Bohn, H. F.; Seidel, R.; Rubach, S.; Speck, T. Acta Biomater. 2013, 9, 6360-6368. doi:10.1016/j.actbio.2013.01.030

10. Li-Beisson, Y.; Pollard, M.; Sauveplane, V.; Pinot, F.; Ohlrogge, J.; Beisson, F. Proc. Natl. Acad. Sci. U. S. A. 2009, 106, 22008-22013. doi:10.1073/pnas.0909090106

11. Whitney, H. M.; Kolle, M.; Andrew, P.; Chittka, L.; Steiner, U.; Glover, B. J. Science 2009, 323, 130-133. doi:10.1126/science.1166256

12. Vignolini, S.; Moyroud, E.; Hingant, T.; Banks, H.; Rudall, P. J.; Steiner, U.; Glover, B. J. New Phytol. 2015, 205, 97-101. doi:10.1111/nph.12958
13. Casado, C. G.; Heredia, A. Physiol. Plant. 2001, 111, 220-224. doi:10.1034/j.1399-3054.2001.1110213.x

14. Domínguez, E.; Heredia-Guerrero, J. A.; Heredia, A. New Phytol. 2011, 189, 938-949. doi:10.1111/j.1469-8137.2010.03553.x

15. Das Gupta, M.; Nath, U. Plant Cell 2015, 27, 2785-2799. doi:10.1105/tpc.15.00196

16. Poethig, R. S.; Sussex, I. M. Planta 1985, 165, 158-169. doi:10.1007/bf00395038

17. Donnelly, P. M.; Bonetta, D.; Tsukaya, H.; Dengler, R. E.; Dengler, N. G. Dev. Biol. (Amsterdam, Neth.) 1999, 215, 407-419. doi:10.1006/dbio.1999.9443

18. Nath, U.; Crawford, B. C. W.; Carpenter, R.; Coen, E. Science 2003, 299, 1404-1407. doi:10.1126/science.1079354

19. Efroni, I.; Eshed, Y.; Lifschitz, E. Plant Cell 2010, 22, 1019-1032. doi:10.1105/tpc.109.073601

20. Andriankaja, M.; Dhondt, S.; De Bodt, S.; Vanhaeren, H.; Coppens, F.; De Milde, L.; Mühlenbock, P.; Skirycz, A.; Gonzalez, N.; Beemster, G. T. S.; Inzé, D. Dev. Cell 2012, 22, 64-78. doi:10.1016/j.devcel.2011.11.011

21. Kuchen, E. E.; Fox, S.; Barbier de Reuille, P.; Kennaway, R.; Bensmihen, S.; Avondo, J.; Calder, G. M.; Southam, P.; Robinson, S.; Bangham, A.; Coen, E. Science 2012, 335, 1092-1096. doi:10.1126/science.1214678

22. Hong, L.; Brown, J.; Segerson, N. A.; Rose, J. K. C.; Roeder, A. H. K. Mol. Plant 2017, 10, 560-574. doi:10.1016/j.molp.2017.01.002

23. Surapaneni, V. A.; Bold, G.; Speck, T.; Thielen, M. R. Soc. Open Sci. 2020, 7, 201319. doi:10.1098/rsos.201319

24. Hay, A.; Yuzammi. Telopea 2000, 9, 1-177. doi:10.7751/telopea20002008

25. Wong, S. Y.; Hoe, Y. C.; Boyce, P. C. Aroideana 2016, 39, 71-100.

26. Hay, A. Sandakania 1996, 7, 1-30.

27. Gorb, E. V.; Gorb, S. N. Entomol. Exp. Appl. 2002, 105, 13-28. doi:10.1046/j.1570-7458.2002.01028.x

28. Gorb, E.; Voigt, D.; Eigenbrode, S. D.; Gorb, S. Arthropod-Plant Interact. 2008, 2, 247-259. doi:10.1007/s11829-008-9049-0

29. Scholz, I.; Bückins, M.; Dolge, L.; Erlinghagen, T.; Weth, A.; Hischen, F.; Mayer, J.; Hoffmann, S.; Riederer, M.; Riedel, M.; Baumgartner, W. J. Exp. Biol. 2010, 213, 1115-1125. doi:10.1242/jeb.035618

30. Prüm, B.; Seidel, R.; Bohn, H. F.; Speck, T. Beilstein J. Nanotechnol. 2012, 3, 57-64. doi:10.3762/bjnano.3.7

31. Voigt, D.; Goodwyn, P. P.; Fujisaki, K. Arthropod-Plant Interact. 2018, 12, 415-421. doi:10.1007/s11829-017-9591-8

32. Bringe, K.; Schumacher, C. F. A.; Schmitz-Eiberger, M.; Steiner, U.; Oerke, E.-C. Phytochemistry 2006, 67, 161-170. doi:10.1016/j.phytochem.2005.10.018

33. O'Toole, J. C.; Cruz, R. T. Plant Physiol. 1980, 65, 428-432. doi:10.1104/pp.65.3.428

34. Grubb, P. J.; Jackson, R. V.; Barberis, I. M.; Bee, J. N.; Coomes, D. A.; Dominy, N. J.; De La Fuente, M. A. S.; Lucas, P. W.; Metcalfe, D. J.; Svenning, J.-C.; Turner, I. M.; Vargas, O. Ann. Bot. (Oxford, U. K.) 2008, 101, 1379-1389. doi:10.1093/aob/mcn047

35. Kadioglu, A.; Terzi, R. Bot. Rev. 2007, 73, 290-302. doi:10.1663/0006-8101(2007)73[290:adamlr]2.0.co;2

36. Martens, P. Protoplasma 1933, 20, 483-515. doi:10.1007/bf02674844

37. Antoniou Kourounioti, R. L.; Band, L. R.; Fozard, J. A.; Hampstead, A.; Lovrics, A.; Moyroud, E.; Vignolini, S.; King, J. R.; Jensen, O. E.; Glover, B. J. J. R. Soc., Interface 2013, 10, 20120847. doi:10.1098/rsif.2012.0847 
38. Bergen, J. Y. Bot. Gaz. (Chicago) 1904, 38, 285-296. doi:10.1086/328550

39. Lee, B.; Priestley, J. H. Ann. Bot. (Oxford, U. K.) 1924, os-38, 525-545. doi:10.1093/oxfordjournals.aob.a089915

40. Juniper, B. E. J. Linn. Soc. London, Bot. 1960, 56, 413-419. doi:10.1111/j.1095-8339.1960.tb02509.x

41. Cerda, E.; Mahadevan, L. Phys. Rev. Lett. 2003, 90, 074302. doi:10.1103/physrevlett.90.074302

42. Chung, J. Y.; Nolte, A. J.; Stafford, C. M. Adv. Mater. (Weinheim, Ger.) 2011, 23, 349-368. doi:10.1002/adma.201001759

43. Lopez-Casado, G.; Matas, A. J.; Dominguez, E.; Cuartero, J.; Heredia, A. J. Exp. Bot. 2007, 58, 3875-3883. doi:10.1093/jxb/erm233

44. Bergmann, J. B.; Moatsou, D.; Surapaneni, V. A.; Thielen, M.; Speck, T.; Wilts, B. D.; Steiner, U. Adv. Mater. Interfaces 2020, 7, 2000129. doi:10.1002/admi.202000129

45. Hoe, Y. C.; Gibernau, M.; Wong, S. Y. Plant Biol. 2018, 20, 563-578. doi:10.1111/plb.12687

46. Kumar, C.; Le Houérou, V.; Speck, T.; Bohn, H. F. R. Soc. Open Sci. 2018, 5, 172132. doi:10.1098/rsos. 172132

47. Leach, R. K. Fundamental Principles of Engineering Nanometrology, 1st ed.; Micro \& nano technologies series; Elsevier, William Andrew: Amsterdam, 2010. doi:10.1016/c2009-0-20339-4

48. $R$ Development Core Team; $R$, version 3.6.1; R Foundation for Statistical Computing: Vienna, 2010.

49. Surapaneni, V. A.; Aust, T.; Speck, T.; Thielen, M. Polarity in cuticular ridge development and insect attachment on leaf surfaces of Schismatoglottis calyptrata (Araceae), Version 2. FreiDok plus, 2021; https://freidok.uni-freiburg.de/data/193850. doi:10.6094/unifr/193850

\section{License and Terms}

This is an open access article licensed under the terms of the Beilstein-Institut Open Access License Agreement (https://www.beilstein-journals.org/bjnano/terms), which is identical to the Creative Commons Attribution 4.0 International License

(https://creativecommons.org/licenses/by/4.0). The reuse of material under this license requires that the author(s), source and license are credited. Third-party material in this article could be subject to other licenses (typically indicated in the credit line), and in this case, users are required to obtain permission from the license holder to reuse the material.

The definitive version of this article is the electronic one which can be found at: https://doi.org/10.3762/bjnano.12.98 